\title{
Gene therapy for bone engineering
}

\author{
Elizabeth Rosado Balmayor ${ }^{1,2}$ and Martijn van Griensven ${ }^{1 *}$ \\ Experimental Trauma Surgery, Department of Trauma Surgery, Klinikum rechts der Isar, Technical University Munich, Munich, Germany \\ 2 Institute for Advanced Science, Technical University Munich, Garching, Germany
}

\section{Edited by:}

Jöns Gunnar Hilborn, Uppsala

University, Sweden

\section{Reviewed by:}

Oommen Varghese, Uppsala

University, Sweden

Mikaël M. Martino, Osaka University,

Japan

\section{*Correspondence:}

Martijn van Griensven, Experimental Trauma Surgery, Klinikum rechts der Isar, Technical University Munich, Ismaninger Strasse 22, Munich

D-81675, Germany

e-mail:vanGriensven@uchir.me.

tum.de
Bone has an intrinsic healing capacity that may be exceeded when the fracture gap is too big or unstable. In that moment, osteogenic measures need to be taken by physicians. It is important to combine cells, scaffolds and growth factors, and the correct mechanical conditions. Growth factors are clinically administered as recombinant proteins. They are, however, expensive and needed in high supraphysiological doses. Moreover, their half-life is short when administered to the fracture. Therefore, gene therapy may be an alternative. Cells can constantly produce the protein of interest in the correct folding, with the physiological glycosylation and in the needed amounts. Genes can be delivered in vivo or ex vivo by viral or non-viral methods. Adenovirus is mostly used. For the non-viral methods, hydrogels and recently sonoporation seem to be promising means. This review will give an overview of recent advancements in gene therapy approaches for bone regeneration strategies.

Keywords: gene therapy, bone regeneration, bone morphogenetic proteins, hydrogel, sonoporation, adenovirus

\section{INTRODUCTION}

Bone tissue can heal relatively well in a natural way. A defect in cortical bone will spontaneously heal if the gap is smaller than $2 \mathrm{~mm}$. A prerequisite for bone healing is absolute fracture stability (Gaston and Simpson, 2007). Unfortunately, trauma, bone tumor resections, or arthritis may lead to larger bone defects that may have a compromised healing. Delayed healing or non-union occurs in $5-10 \%$ of all fractures and $20 \%$ of high impact fractures (Brydone et al., 2010). This impaired healing is caused by the body's inability to regenerate the bone and additional surgical interventions, besides stabilization, may be needed to replace the lost bone. Autografts, allografts, and bone grafts substitutes are mainly used for this purpose in an attempt to fill these non-healing bone defects. Osteogenic growth factors may also be added to the bone graft substitutes in order to kick-start or accelerate bone healing. More recently, autologous stem cells derived from bone marrow have been administered to enhance the healing of the non-union bone defects.

Thus, the important prerequisites for bone healing are: (i) cells with osteogenic potential, (ii) osteoconductive matrix, (iii) osteoinductive stimulus, and (iv) a mechanical stable environment (Giannoudis et al., 2007). The authors named this the "diamond concept" and all components must be active for a successful bone-union to occur.

Recombinant growth factors, however, are expensive and cumbersome to produce. This is because, eukaryotic cells are needed in order to have a correct folding as well as glycosylation of the protein. Furthermore, once transferred to the body, the growth factors have a short half-life and need to be administered in high supraphysiological concentrations. Therefore, gene therapy may be an alternative (Figure 1). Indeed, there are several advantages of gene delivery over protein delivery, which are well supported by a fair number of scientific studies. The most relevant advantages of gene therapy include the flexibility to express the protein locally and focally, or in a disseminated fashion, as needed. Of note, gene therapy brings the possibility for intra-cellular production of proteins. Thus, this facilitates therapeutic pathways to take place. Unlike its recombinant equivalent, the protein delivered via gene transfer will be nascent and uncontaminated by a variable percentage of incorrectly folded and possibly antigenic molecules (Evans, 2012). Moreover, additional advantages of gene delivery include the ability to express proteins for extended periods of time and the level of transgene expression can be regulated.

A second aspect of the need of high protein doses is possible side effects that may hamper safety of the therapy. Adverse events for the use of BMP-2 mainly in spinal fusion are ectopic bone formation, swelling, seroma, retrograde ejaculation, dysphagia, and tumor formation (Woo, 2012; Fu et al., 2013). Swelling due to use of BMP-2 in anterior cervical spine fusion was observed in $28 \%$ of the patients (Smucker et al., 2006). In anterior interlumbar interbody fusion, several adverse events may occur. Retrograde ejaculation occurs in $6.3-7.4 \%$ of the patients, which may lead to a two times increased incidence of urinary retention (Carragee et al., 2011; Comer et al., 2012). A controversy exists concerning cancer risk upon BMP-2 administration. Several studies conclude that no increased cancer risk occurs when BMP-2 is used for spinal arthrodesis (Cooper and Kou, 2013; Kelly et al., 2014). However, Carragee et al. (2013) reported that high doses of BMP-2 in spinal arthrodesis result in a five times increased cancer risk 2 years after surgery.

Thus, gene therapy often reduces the amounts of therapeutic molecules. It may only need to be delivered once and in a relatively small amount (Evans, 2012). Thereby, the adverse events described above may not occur. The cancer risk e.g., was only increased when high doses of BMP-2 were used and by using gene therapy, only low amounts of protein are produced not leading 


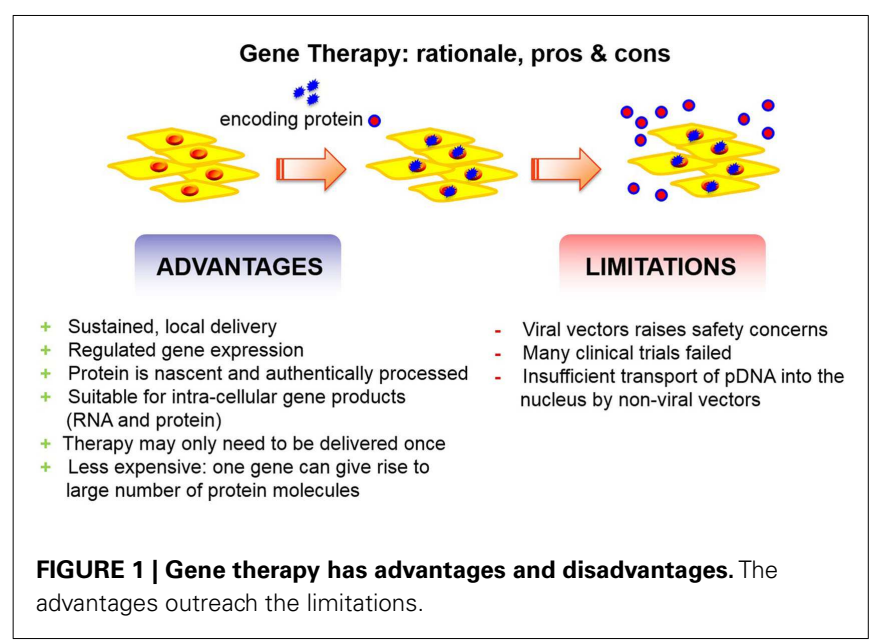

to this increased cancer risk. In addition to its therapeutic potential, gene delivery is a valuable experimental tool for laboratory research into the biology of bone. Translating these facts to the osteology area, gene transfer to bone has demonstrated its huge therapeutic capabilities. As a matter of fact, gene transfer using viral vectors has already shown that bone healing and treatment of other bone disorders such as bone tumors or osteogenesis imperfecta can be possible. Although limitations are associated with viral vectors, studies clearly reveal the strong advantages of using gene therapy over treatments with the recombinant protein. Indeed, integration occurs even with integration non-competent viruses such as adeno-associated viruses (Kaeppel et al., 2013). However, this did not lead to tumorigenicity. Another important issue is the fact that preexisting antibodies or memory T-cells may diminish the efficacy of AAV gene therapy (Mingozzi and High, 2013). To screen patients beforehand may improve the effectiveness. However, many patients may than be excluded as AAV are commonly encountered in normal life and thereby an immune-memory has developed. Nevertheless, there is a believable proof of principle in both in vitro and animal model experiments that gene transfer can be successfully used to regenerate bone (Evans, 2012).

\section{HISTORY OF GENE THERAPY}

The first idea related with a gene therapy approach evolved as early as 1966 and was mentioned by Edward Tatum when he speculated that viruses could be used effectively to introduce new genes into defective cells of particular organs (Tatum, 1966). Tatum also suggested the first definition of a field that was called "human genetic engineering" at that time. He defined human genetic engineering as the alteration of existing genes in an individual and stated that the first successful genetic engineering would be performed with the patient's own cells (Tatum, 1966). One year later, Lederberg mentioned the term "virogenic therapy" in a publication in the Washington Post in which he defended the idea that viruses could be used to transfer DNA molecules that could encode for a therapeutic entity into cells of patients suffering from hereditary defects (Lederberg, 1968). In 1969, the first isolation of a gene succeeded by Beckwith (1969) promising a brilliant future to the so-called human genetic engineering. However, growing debates on social and ethical implications accompanied the field throughout the 1960s and 1970s. The gene therapy concept was criticized as being remote and improbable, even unnecessary. Several prominent scientists rejected all the rationale behind gene therapy and the use of DNA with therapeutically aims (Burnet, 1971). Together with this hostile background, Stanfield Rogers failed, when he performed the first attempt at human gene therapy, in the late 1960s. He injected the Shope papilloma virus into patients with arginase deficiency. His assumption that the virus contained an arginase gene and that would induce arginase expression or leads to the preferential growth of cells with higher arginase activity, could not be proven. The treated patients did not show any effect on their arginase levels after injection of the virus. In 1980, a second attempt is registered when Cline and colleagues tried to transfect the $\beta$-globin gene into human bone marrow cells. The cells were subsequently transplanted into patients suffering from thalassemia. Their trial was criticized for both scientific and procedural reasons (Wolff and Lederberg, 1994). Both trials lacked a sound practice and well-proven cell culture and animal experiments.

It was not until the development of recombinant DNA technology together with early transfection and cell culture techniques that major progress was made in gene transfer. Subsequently, several disease-related genes (e.g., herpes TK gene, APRT, and human HPRT) were successfully transferred into mammalian cells proving the feasibility of the technique. Therefore, the first approved gene therapy case took place at the NIH for treating a genetic defect that caused a severe immune system deficiency (ADA-SCID) in 1990. The results were successful, however temporary. Up to the present, a fair number of clinical trials for chronic and acute lymphocytic leukemia, multiple myeloma, thalassemia, coronary artery disease, HIV, and retinal diseases among others have been or are being conducted using a gene therapy approach.

\section{DELIVERY PLATFORMS FOR GENE THERAPY FOR BONE ENGINEERING}

Despite the above-mentioned advancements, transfections of bone-related cells, bone-derived stem cells, or bone tissue aiming to bone regeneration have hardly been performed. Different strategies exist to perform gene therapy for bone engineering:

1. In vivo
a. Viral
b. Non-viral

2. Ex vivo
a. Viral
b. Non-viral

In the in vivo approach, the vector (viral or non-viral) is administered to the fracture gap and resident cells are expected to be transfected (van Griensven et al., 2002). They will locally produce the osteogenic protein. The administration can be via direct injection or associated with a biomaterial. The latter combination of vector and biomaterial is called gene activated matrix (GAM). Regarding the ex vivo approach, one does not rely on the cells to be transfected in situ. Autologous cells will be harvested [e.g., mesenchymal stem cells from bone marrow (BMSC) or adipose tissue (AdMSC)] and transduced outside the body. The transduced 
cells are subsequently implanted in the fracture gap. Again, direct injection or using a biomaterial as carrier is the main method of application.

\section{VIRAL GENE TRANSDUCTION}

Viruses are widely used as their mode of action is to transfect mammalian cells with their genetic material. Most used virus types for gene therapy are adenoviruses, adeno-associated viruses, lentiviruses, and retroviruses. Recombinant viral vectors are widely used. It has the ability to infect different cell types with high efficiency. No differences in efficiency are reported for using dividing or non-dividing cells. The gene of interest is not incorporated in the human genome and will be non-detectable after several cell cycles. Reports in bone regeneration mainly employ adeno- or retrovirus vectors carrying plasmids that encode for bone morphogenetic proteins (BMPs) (Park et al., 2003; Tsuda et al., 2003). In addition, GAM have been also used in vivo for bone healing. Those are mainly based on the loading of BMPs plasmid/viral vectors complexes onto biomaterials (e.g., collagen, chitosan, polyesters, and calcium phosphates) to be implanted at the defect site (Chang et al., 2010; Zhang et al., 2011).

Rat femoral defects have been treated with adenoviral constructs encoding BMP-2, Runx2, or VEGF. BMP-2 healed the femoral defects dose-dependently (Betz et al., 2007b) upon direct percutaneous injection (Betz et al., 2006). When the authors did not immediately apply the vector, but performed delayed injection, the results were even more pronounced (Betz et al., 2007a). When performing a GAM approach using transduced muscle or adipose grafts, no difference could be obtained with autograft (Evans et al., 2009; Betz et al., 2013). Similar effects were obtained with a hydrogel formulation (Sonnet et al., 2013). When using MSC transduced with adenoviral BMP-2, efficient healing could also be detected (Lieberman et al., 1999; Peterson et al., 2005). Using the more downstream runx2 signal transduction molecule within an adenoviral vector, induced higher bone mineral density upon direct injection in the bone marrow of a rat femur (Bhat et al., 2008). However, not only osteogenic genes result in improved fracture healing, also inducing angiogenesis by a VEGF-adenoviral vector was able to promote bone formation (Tarkka et al., 2003).

Besides rat studies, also larger animals are used such as rabbits, sheep, and pig. The latter is mainly studied for calvarial defects. A rabbit femur segmental defect could be healed by injection of a BMP-2 encoding adenoviral vector (Baltzer et al., 2000). Also in sheep, this treatment was successful (Egermann et al., 2006b). Even when the sheep were osteoporotic, the BMP-2 could induce fracture healing (Egermann et al., 2006a). Goat have similar physiologic properties as sheep. Tibial defects in goats were treated with a scaffold composed of biphasic calcined bone and autologous BMSC transduced with human BMP-2. Five goats showed complete healing and three partial healing after 26 weeks (Dai et al., 2005). However, a temporary cellular and persistent humoral immune responses against adenovirus could be detected (Xu et al., 2005).

\section{NON-VIRAL GENE THERAPY FOR BONE ENGINEERING}

Despite all the above-mentioned restraints, viruses currently remain the carriers of choice in most of the gene therapy studies and clinical trials. However, safety concerns are continuously raised associated with their use. This is based on the fact that they naturally transfer their genetic material very efficiently into the cells. For viral gene therapy, the viral genome is modified by removing the sequences that contribute to their pathogenicity (Evans, 2012). However, the safety concerns are constantly growing together with the fact that viral vectors can be expensive and their production is complicated (Schleef et al., 2010; Elsabahy et al., 2011).

Therefore, high interest has been placed in the use of nonviral vectors during the last two decades. Cationic polymers, lipids, peptides and even calcium phosphate, and other inorganic nanomaterials have been explored for their capabilities as carriers of genetic information into a target cell for in vivo gene therapy (Loh and Lee, 2012). Among them, cationic liposomes and cationic polymers are by far the most widely utilized carriers for gene and nucleic acid delivery today (Tros de Ilarduya et al., 2010; Won et al., 2011). Because of their opposite surface charge, they are commonly utilized for gene transfer by forming a complex (lipoplexes or polyplexes) with negatively charged DNA molecules. A common disadvantage of those systems is their still relatively low transfection efficiency when compared to viral vectors, especially when "difficult-to-transfect cells" such as MSCs represent the target cell. Although it is worth mentioning that progress in lipid development has achieved quite satisfactory levels of transfections in recently published studies (Jain et al., 2013; Locatelli et al., 2013; Sarker et al., 2013). Unfortunately, they often have toxic effects on the cells. Both cationic lipids and polymers are not biodegradable and therefore, the risk of their accumulation in the body is high. Based on all the aforementioned facts, it can be concluded that the development of highly efficient and less toxic gene carriers is the most challenging work in the field of non-viral gene therapy (Medina-Kauwe et al., 2005; Shan et al., 2012).

The work of Tomas' group is encouraging, demonstrating a successful transfection of adipose tissue-derived MSCs with a G4 PAMAM/BMP-2 plasmid dendriplex inducing this cells to differentiate into the osteogenic phenotype, even when only low transfection efficiencies were achieved (Santos et al., 2009). Also delivering BMP-2 cDNA in an alginate hydrogel is promising. Biologically active BMP-2 is released from the BMSC present in the gel over a period of 5 weeks. This leads in vivo to ectopic osteogenesis (Wegman et al., 2011). Other hydrogels such as fibrin or hyaluronic acid may also be used as carriers for nucleic acid vectors (Schillinger et al., 2008; des Rieux et al., 2009; Lei et al., 2010, 2011). They can be used for delivering osteogenic genes and induce bone formation and accelerate fracture healing (Yang et al., 2012; Kaipel et al., 2014).

Another novel method for transducing cells is the so-called sonoporation (Mehier-Humbert et al., 2005; Li et al., 2009). Ultrasound is used in combination with microbubbles to transfect cells. Therefore, a novel osteoinductive non-viral in vivo gene therapy approach using sonoporation was investigated in ectopic and orthotopic models (Sheyn et al., 2008; Feichtinger et al., 2014b). BMP-2 and BMP-7 co-expression plasmids were repeatedly applied for 5 days with or without sonoporation. Transduction efficiency was observed using a luciferase plasmid and bioluminescence imaging in an ectopic model. Luminescence 
demonstrated increased transduction efficiency in sonoporated animals in comparison with passive gene delivery (Feichtinger et al., 2014b). Using osteogenic plasmids like BMP-2/BMP-7 or BMP-9, enhanced ectopic bone formation was detected for sonoporation compared to passive gene delivery (Sheyn et al., 2008; Osawa et al., 2009; Feichtinger et al., 2014b). Also orthotopic application in a rat femur non-union model demonstrated similar results using sonoporation. Sonoporated animals showed an increased union rate (Feichtinger et al., 2014b).

\section{NOVEL APPROACHES OTHER THAN GROWTH FACTORS}

Besides the use of genes for BMP or other growth factors, much attention has been given recently to miRNA use with therapeutic aims. miRNAs are small (approximately $20 \mathrm{nt}$ ), non-coding RNAs. Over 4,000 miRNAs have been identified so far in the human genome. They regulate many biological processes in the human body. They are known to adjust and switch regulatory circuits governing tissue repair. Key elements of tissue repair such as stem cell biology, inflammation, and angiogenesis are under control of a network of miRNAs (Sen, 2011). They were first discovered associated with cancer treatments and cardiovascular diseases. Recently, several miRNAs have been identified so far to be associated with bone pathologies (Seeliger et al., 2014). For example, miRNA-218 has been reported to be a pro-osteoblastic factors by acting on Wnt inhibitors. A DNA aptamer that binds sclerostin has a similar activity (Shum et al., 2011). miRNA-148a is a proosteoclastic factor by blocking MAFB signaling (van Wijnen et al., 2013). In addition to miRNA-218, 10 other miRNAs have been identified to control osteoblast differentiation and are expressed in osteoblastic cells (i.e., miRNA-23a, miRNA-30c, miRNA-34c, miRNA-133a, miRNA-135a, miRNA-137, miRNA-204, miRNA205, miRNA-217, and miRNA-338) (van Wijnen et al., 2013). From a therapeutic perspective, in vivo approaches that promote the activity of pro-osteoblastic miRNA or inhibit pro-osteoclastic miRNAs are highly attractive for stimulating bone formation. However, efficient tools for delivering those miRNA mimics (e.g., to stimulate pro-osteoblastic miRNA) or inhibitors (e.g., to block pro-osteoclastic miRNAs) to specific target tissue are limited. Two possibilities were shown by Li et al. They could show that transfected MSCs with miRNA26a in hydroxalapatite-tricalcium phosphate scaffolds induced bone formation subcutaneously. Furthermore, a hydrogel delivery system consisting of HyStem-HP could enhance bone regeneration in a rat calvarial model (Li et al., 2013). Using miRNA transfected MSCs is common. Transfection of MSCs with miRNAs can be improved using magnetic nanoparticles (Schade et al., 2013, 2014). miRNA-31 transfected MSCs in a polyglycol sebacate scaffold accelerated and improved the healing of a rat critical-size calvarial defect (Deng et al., 2014). miRNA-138 transfected MSCs on a cell sheet and implanted subcutaneously in immunocompromised mice showed bone formation (Yan et al., 2014).

Besides the modulating miRNA, mRNA can be blocked using silencing RNA ( siRNA). Depending on the target, osteogenesis can be promoted. Using siRNA against glucocorticoid receptors encapsulated in poly(lactid-co-glycolic acid) resulted in an upregulation of alkaline phosphatase and RunX2 in MSCs (Hong et al., 2012). Similar results on these two genes were obtained using siRNA against Noggin delivered in PEG hydrogels (Nguyen et al., 2014). The RunX2 pathway is very important for osteogenesis and the siRNA against guanine nucleotide-binding protein $\alpha$-stimulating activity polypeptide 1 is modulating this. It was shown that in MSCs treatment with this siRNA lead to upregulation of collagen type I, osteopontin, and alkaline phosphatase (Rios et al., 2012). This siRNA and siRNA against prolyl hydroxylase domaincontaining protein 2 increased bone volume when implanted in a fibroin-chitosan cage above ovine periosteum in vivo (Rios et al., 2012). This biomaterial seems favorable for the delivery of siRNA. Chitosan sponges were loaded with siRNA against casein kinase 2 interaction protein 1 and soluble vascular endothelial growth factor receptor 1 . This induced expression of osteocalcin, alkaline phosphatase, and vascular endothelial growth factor in MSCs. Moreover, mineralization as evidenced by alizarin red staining was increased. Furthermore, administration in a critical-size calvarial model resulted in accelerated, complete bone regeneration (Jia et al., 2014). Finally, siRNA against LNK protein accelerated femur fracture healing in a mouse model. This was accompanied by increased osteoblast activity (Kawakami et al., 2013).

\section{OPTIMIZING DELIVERY, EXPRESSION, AND FUNCTION}

All of the above-mentioned novel approaches need optimization. The genes need to be locally expressed in specific target cells (spatial control). This may be achieved by using aptamers that specifically bind osteogenic progenitor cells (Ardjomandi et al., 2013). Another possibility is using a tissue specific promotor for conditional expression of the gene of interest (Lian et al., 2000). Furthermore, the level of gene expression needs to be controlled. This may be achieved by using molecular sensors and negative feedback loops (Kaempfer, 2003). Moreover, the period of expression needs to be controlled. This may be achieved by using TET-on/TET-off systems and administration of doxycycline (Feichtinger et al., 2014a). Finally, angiogenesis is important for bone regeneration. Combining osteogenic and angiogenic factors may enhance bone formation as shown already in the siRNA approach against guanine nucleotide-binding protein $\alpha$-stimulating activity polypeptide 1 and prolyl hydroxylase domain-containing protein 2 (Rios et al., 2012). But also BMP and vascular endothelial growth factor gene co-delivery may enhance osteogenesis (Huang et al., 2005; Samee et al., 2008; Wu et al., 2012).

\section{CONCLUSION}

Today, the scientific community worldwide has identified main problems and limitations behind the current gene therapy approach. However, it remains undoubted that a safe and efficient gene therapy approach could have a huge impact on non-curable diseases today. Therefore, a fair number of scientific efforts are aimed to find solutions and optimize this approach. Currently, we are aware of the need for a therapeutically functional DNA after it has been transported to the nuclei. The risks of stimulating the immune system in a way that the effectiveness of the therapy will be diminished are always present. The chances for tumor formation as a consequence of a wrongly integrated DNA have also occurred in earlier clinical trials. Viruses represent one of the most efficient means to transfer the genetic information to the cells. However, 
they also carry a variety of strong limitations. Some examples are toxicity, immune responses, and the potential risk for recovering their ability of causing diseases.

Gene therapy for bone regeneration is important and should be further investigated. Combinations of different genes in association with biomaterials are in our opinion the most promising to bring the field forward. At the moment, one clinical trial has just started November 11th 2014 with a GAM based on collagen-hydroxyapatite including the gene for vascular endothelial growth factor-A165 to treat alveolar bone loss (clinicaltrials.gov: NCT02293031). No other clinical trials are ongoing at the moment. We think that in the near future gene therapy for bone regeneration will not be implemented in the clinical arena. However, as science and technology progress, clinical translation is not out of reach.

\section{REFERENCES}

Ardjomandi, N., Niederlaender, J., Aicher, W. K., Reinert, S., Schweizer, E., Wendel, H. P., et al. (2013). Identification of an aptamer binding to human osteogenicinduced progenitor cells. Nucleic Acid Ther. 23, 44-61. doi:10.1089/nat.2012.0349

Baltzer, A. W., Lattermann, C., Whalen, J. D., Wooley, P., Weiss, K., Grimm, M., et al. (2000). Genetic enhancement of fracture repair: healing of an experimental segmental defect by adenoviral transfer of the BMP-2 gene. Gene Ther. 7, 734-739. doi:10.1038/sj.gt.3301166

Beckwith, J. (1969). Scientists isolate single gene in step to heredity control. The New York Times. 72.

Betz, O. B., Betz, V. M., Nazarian, A., Egermann, M., Gerstenfeld, L. C., Einhorn, T. A., et al. (2007a). Delayed administration of adenoviral BMP-2 vector improves the formation of bone in osseous defects. Gene Ther. 14, 1039-1044. doi:10.1038/sj.gt.3302956

Betz, V. M., Betz, O. B., Glatt, V., Gerstenfeld, L. C., Einhorn, T. A., Bouxsein, M. L., et al. (2007b). Healing of segmental bone defects by direct percutaneous gene delivery: effect of vector dose. Hum. Gene Ther. 18, 907-915. doi:10.1089/hum.2007.077

Betz, O. B., Betz, V. M., Nazarian, A., Pilapil, C. G., Vrahas, M. S., Bouxsein, M. L., et al. (2006). Direct percutaneous gene delivery to enhance healing of segmental bone defects. J. Bone Joint Surg. Am. 88, 355-365. doi:10.2106/JBJS.E.00464

Betz, O. B., Betz, V. M., Schroder, C., Penzkofer, R., Gottlinger, M., MayerWagner, S., et al. (2013). Repair of large segmental bone defects: BMP-2 gene activated muscle grafts vs. autologous bone grafting. BMC Biotechnol. 13:65. doi:10.1186/1472-6750-13-65

Bhat, B. M., Robinson, J. A., Coleburn, V. E., Zhao, W., and Kharode, Y. (2008). Evidence of in vivo osteoinduction in adult rat bone by adeno-Runx2 intra-femoral delivery. J. Cell. Biochem. 103, 1912-1924. doi:10.1002/jcb.21581

Brydone, A. S., Meek, D., and Maclaine, S. (2010). Bone grafting, orthopaedic biomaterials, and the clinical need for bone engineering. Proc. Inst. Mech. Eng. H 224, 1329-1343. doi:10.1243/09544119JEIM770

Burnet, M. (1971). Genes, Dreams and Reality. New York, NY: Basic Books.

Carragee, E. J., Chu, G., Rohatgi, R., Hurwitz, E. L., Weiner, B. K., Yoon, S. T., et al. (2013). Cancer risk after use of recombinant bone morphogenetic protein-2 for spinal arthrodesis. J. Bone Joint Surg. Am. 95, 1537-1545. doi:10.2106/jbjs.l.01483

Carragee, E. J., Mitsunaga, K. A., Hurwitz, E. L., and Scuderi, G. J. (2011). Retrograde ejaculation after anterior lumbar interbody fusion using rhBMP-2: a cohort controlled study. Spine J. 11, 511-516. doi:10.1016/j.spinee.2011.02.013

Chang, S. C., Chung, H. Y., Tai, C. L., Chen, P. K., Lin, T. M., and Jeng, L. B. (2010). Repair of large cranial defects by hBMP-2 expressing bone marrow stromal cells: comparison between alginate and collagen type I systems. J. Biomed. Mater. Res. A 94, 433-441. doi:10.1002/jbm.a.32685

Comer, G. C., Smith, M. W., Hurwitz, E. L., Mitsunaga, K. A., Kessler, R., and Carragee, E. J. (2012). Retrograde ejaculation after anterior lumbar interbody fusion with and without bone morphogenetic protein-2 augmentation: a 10-year cohort controlled study. Spine J. 12, 881-890. doi:10.1016/j.spinee.2012.09.040

Cooper, G. S., and Kou, T. D. (2013). Risk of cancer after lumbar fusion surgery with recombinant human bone morphogenic protein-2 (rh-BMP-2). Spine 38, 1862-1868. doi:10.1097/BRS.0b013e3182a3d3b4
Dai, K. R., Xu, X. L., Tang, T. T., Zhu, Z. A., Yu, C. F., Lou, J. R., et al. (2005). Repairing of goat tibial bone defects with BMP-2 gene-modified tissue-engineered bone. Calcif. Tissue Int. 77, 55-61. doi:10.1007/s00223-004-0095-Z

Deng, Y., Bi, X., Zhou, H., You, Z., Wang, Y., Gu, P., et al. (2014). Repair of criticalsized bone defects with anti-miR-31-expressing bone marrow stromal stem cells and poly(glycerol sebacate) scaffolds. Eur. Cell. Mater. 27, 13-24.

des Rieux, A., Shikanov, A., and Shea, L. D. (2009). Fibrin hydrogels for non-viral vector delivery in vitro. J. Control Release 136, 148-154. doi:10.1016/j.jconrel. 2009.02.004

Egermann, M., Baltzer, A. W., Adamaszek, S., Evans, C., Robbins, P., Schneider, E., et al. (2006a). Direct adenoviral transfer of bone morphogenetic protein-2 cDNA enhances fracture healing in osteoporotic sheep. Hum. Gene Ther. 17, 507-517. doi:10.1089/hum.2006.17.507

Egermann, M., Lill, C. A., Griesbeck, K., Evans, C. H., Robbins, P. D., Schneider, E., et al. (2006b). Effect of BMP-2 gene transfer on bone healing in sheep. Gene Ther. 13, 1290-1299. doi:10.1038/sj.gt.3302785

Elsabahy, M., Nazarali, A., and Foldvari, M. (2011). Non-viral nucleic acid delivery: key challenges and future directions. Curr. Drug Deliv. 8, 235-244. doi:10.2174/ 156720111795256174

Evans, C. H. (2012). Gene delivery to bone. Adv. Drug Deliv. Rev. 64, 1331-1340. doi:10.1016/j.addr.2012.03.013

Evans, C. H., Liu, F. J., Glatt, V., Hoyland, J. A., Kirker-Head, C., Walsh, A., et al. (2009). Use of genetically modified muscle and fat grafts to repair defects in bone and cartilage. Eur. Cell. Mater. 18, 96-111.

Feichtinger, G. A., Hacobian, A., Hofmann, A. T., Wassermann, K., Zimmermann, A., Van Griensven, M., et al. (2014a). Constitutive and inducible coexpression systems for non-viral osteoinductive gene therapy. Eur. Cell. Mater. 27, 166-184.

Feichtinger, G. A., Hofmann, A. T., Slezak, P., Schuetzenberger, S., Kaipel, M., Schwartz, E., et al. (2014b). Sonoporation increases therapeutic efficacy of inducible and constitutive BMP2/7 in vivo gene delivery. Hum. Gene Ther. Methods 25, 57-71. doi:10.1089/hgtb.2013.113

Fu, R., Selph, S., McDonagh, M., Peterson, K., Tiwari, A., Chou, R., et al. (2013). Effectiveness and harms of recombinant human bone morphogenetic protein-2 in spine fusion: a systematic review and meta-analysis. Ann. Intern. Med. 158, 890-902. doi:10.7326/0003-4819-158-12-201306180-00006

Gaston, M. S., and Simpson, A. H. (2007). Inhibition of fracture healing. J. Bone Joint Surg. Br. 89, 1553-1560. doi:10.1302/0301-620X.89B12.19671

Giannoudis, P. V., Einhorn, T. A., and Marsh, D. (2007). Fracture healing: the diamond concept. Injury 38(Suppl. 4), S3-S6. doi:10.1016/S0020-1383(08)70003-2

Hong, L., Wei, N., Joshi, V., Yu, Y., Kim, N., Krishnamachari, Y., et al. (2012). Effects of glucocorticoid receptor small interfering RNA delivered using poly lactic-co-glycolic acid microparticles on proliferation and differentiation capabilities of human mesenchymal stromal cells. Tissue Eng. Part A 18, 775-784. doi:10.1089/ten.TEA.2011.0432

Huang, Y. C., Kaigler, D., Rice, K. G., Krebsbach, P. H., and Mooney, D. J. (2005). Combined angiogenic and osteogenic factor delivery enhances bone marrow stromal cell-driven bone regeneration. J. Bone Miner. Res. 20, 848-857. doi:10.1359/jbmr.041226

Jain, S., Kumar, S., Agrawal, A. K., Thanki, K., and Banerjee, U. C. (2013). Enhanced transfection efficiency and reduced cytotoxicity of novel lipid-polymer hybrid nanoplexes. Mol. Pharm. 10, 2416-2425. doi:10.1021/mp400036w

Jia, S., Yang, X., Song, W., Wang, L., Fang, K., Hu, Z., et al. (2014). Incorporation of osteogenic and angiogenic small interfering RNAs into chitosan sponge for bone tissue engineering. Int. J. Nanomedicine 9, 5307-5316. doi:10.2147/ijn.s70457

Kaempfer, R. (2003). RNA sensors: novel regulators of gene expression. EMBO Rep. 4, 1043-1047. doi:10.1038/sj.embor.embor7400005

Kaeppel, C., Beattie, S. G., Fronza, R., Van Logtenstein, R., Salmon, F., Schmidt, S., et al. (2013). A largely random AAV integration profile after LPLD gene therapy. Nat. Med. 19, 889-891. doi:10.1038/nm.3230

Kaipel, M., Schutzenberger, S., Hofmann, A. T., Ferguson, J., Nau, T., Redl, H., et al. (2014). Evaluation of fibrin-based gene-activated matrices for BMP2/7 plasmid codelivery in a rat nonunion model. Int. Orthop. 38, 2607-2613. doi:10.1007/s00264-014-2499-3

Kawakami, Y., Ii, M., Matsumoto, T., Kawamoto, A., Kuroda, R., Akimaru, H., et al. (2013). A small interfering RNA targeting Lnk accelerates bone fracture healing with early neovascularization. Lab. Invest. 93, 1036-1053. doi:10.1038/labinvest. 2013.93 
Kelly, M. P., Savage, J. W., Bentzen, S. M., Hsu, W. K., Ellison, S. A., and Anderson, P. A. (2014). Cancer risk from bone morphogenetic protein exposure in spinal arthrodesis. J. Bone Joint Surg. Am. 96, 1417-1422. doi:10.2106/jbjs.m.01190

Lederberg, J. (1968). DNA breakthrough points way to therapy by virus. Washington Post.

Lei, Y., Huang, S., Sharif-Kashani, P., Chen, Y., Kavehpour, P., and Segura, T. (2010). Incorporation of active DNA/cationic polymer polyplexes into hydrogel scaffolds. Biomaterials 31, 9106-9116. doi:10.1016/j.biomaterials.2010.08.016

Lei, Y., Rahim, M., Ng, Q., and Segura, T. (2011). Hyaluronic acid and fibrin hydrogels with concentrated DNA/PEI polyplexes for local gene delivery. J. Control Release 153, 255-261. doi:10.1016/j.jconrel.2011.01.028

Li, Y., Fan, L., Liu, S., Liu, W., Zhang, H., Zhou, T., et al. (2013). The promotion of bone regeneration through positive regulation of angiogenic-osteogenic coupling using microRNA-26a. Biomaterials 34, 5048-5058. doi:10.1016/j. biomaterials.2013.03.052

Li, Y. S., Davidson, E., Reid, C. N., and McHale, A. P. (2009). Optimising ultrasoundmediated gene transfer (sonoporation) in vitro and prolonged expression of a transgene in vivo: potential applications for gene therapy of cancer. Cancer Lett. 273, 62-69. doi:10.1016/j.canlet.2008.07.030

Lian, J. B., Stein, G. S., Stein, J. L., and Van Wijnen, A. J. (2000). Marrow transplantation and targeted gene therapy to the skeleton. Clin. Orthop. Relat. Res. (Suppl. 379):S146-S155. doi:10.1097/00003086-200010001-00019

Lieberman, J. R., Daluiski, A., Stevenson, S., Wu, L., McAllister, P., Lee, Y. P., et al. (1999). The effect of regional gene therapy with bone morphogenetic protein-2producing bone-marrow cells on the repair of segmental femoral defects in rats. J. Bone Joint Surg. Am. 81, 905-917.

Locatelli, P., Olea, F. D., Hnatiuk, A., Sepulveda, D., Perez Saez, J. M., Arguello, R., et al. (2013). Efficient plasmid-mediated gene transfection of ovine bone marrow mesenchymal stromal cells. Cytotherapy 15, 163-170. doi:10.1016/j.jcyt.2012.11.004

Loh, X. J., and Lee, T. C. (2012). Gene delivery by functional inorganic nanocarriers. Recent Pat. DNA Gene Seq. 6, 108-114. doi:10.2174/187221512801327361

Medina-Kauwe, L. K., Xie, J., and Hamm-Alvarez, S. (2005). Intracellular trafficking of nonviral vectors. Gene Ther. 12, 1734-1751. doi:10.1038/sj.gt.3302592

Mehier-Humbert, S., Bettinger, T., Yan, F., and Guy, R. H. (2005). Ultrasoundmediated gene delivery: kinetics of plasmid internalization and gene expression. J. Control Release 104, 203-211. doi:10.1016/j.jconrel.2005.01.011

Mingozzi, F., and High, K. A. (2013). Immune responses to AAV vectors: overcoming barriers to successful gene therapy. Blood 122, 23-36. doi:10.1182/blood-201301-306647

Nguyen, M. K., Jeon, O., Krebs, M. D., Schapira, D., and Alsberg, E. (2014). Sustained localized presentation of RNA interfering molecules from in situ forming hydrogels to guide stem cell osteogenic differentiation. Biomaterials 35, 6278-6286. doi:10.1016/j.biomaterials.2014.04.048

Osawa, K., Okubo, Y., Nakao, K., Koyama, N., and Bessho, K. (2009). Osteoinduction by microbubble-enhanced transcutaneous sonoporation of human bone morphogenetic protein-2. J. Gene Med. 11, 633-641. doi:10.1002/jgm.1331

Park, J., Ries, J., Gelse, K., Kloss, F., Von Der Mark, K., Wiltfang, J., et al. (2003). Bone regeneration in critical size defects by cell-mediated BMP-2 gene transfer: a comparison of adenoviral vectors and liposomes. Gene Ther. 10, 1089-1098. doi:10.1038/sj.gt.3301960

Peterson, B., Zhang, J., Iglesias, R., Kabo, M., Hedrick, M., Benhaim, P., et al. (2005). Healing of critically sized femoral defects, using genetically modified mesenchymal stem cells from human adipose tissue. Tissue Eng. 11, 120-129. doi:10.1089/ten.2005.11.120

Rios, C. N., Skoracki, R. J., and Mathur, A. B. (2012). GNAS1 and PHD2 shortinterfering RNA support bone regeneration in vitro and in an in vivo sheep model. Clin. Orthop. Relat. Res. 470, 2541-2553. doi:10.1007/s11999-012-2475-4

Samee, M., Kasugai, S., Kondo, H., Ohya, K., Shimokawa, H., and Kuroda, S. (2008). Bone morphogenetic protein-2 (BMP-2) and vascular endothelial growth factor (VEGF) transfection to human periosteal cells enhances osteoblast differentiation and bone formation. J. Pharmacol. Sci. 108, 18-31. doi:10.1254/jphs. 08036FP

Santos, J. L., Oramas, E., Pego, A. P., Granja, P. L., and Tomas, H. (2009). Osteogenic differentiation of mesenchymal stem cells using PAMAM dendrimers as gene delivery vectors. J. Control Release 134, 141-148. doi:10.1016/j.jconrel. 2008.11.007

Sarker, S. R., Aoshima, Y., Hokama, R., Inoue, T., Sou, K., and Takeoka, S. (2013). Arginine-based cationic liposomes for efficient in vitro plasmid DNA delivery with low cytotoxicity. Int. J. Nanomedicine 8, 1361-1375. doi:10.2147/IJN.S38903
Schade, A., Delyagina, E., Scharfenberg, D., Skorska, A., Lux, C., David, R., et al. (2013). Innovative strategy for microRNA delivery in human mesenchymal stem cells via magnetic nanoparticles. Int. J. Mol. Sci. 14, 10710-10726. doi:10.3390/ijms140610710

Schade, A., Muller, P., Delyagina, E., Voronina, N., Skorska, A., Lux, C., et al. (2014). Magnetic nanoparticle based nonviral microRNA delivery into freshly isolated CD105(+) hMSCs. Stem Cells Int. 2014, 197154. doi:10.1155/2014/197154

Schillinger, U., Wexel, G., Hacker, C., Kullmer, M., Koch, C., Gerg, M., et al. (2008). A fibrin glue composition as carrier for nucleic acid vectors. Pharm. Res. 25, 2946-2962. doi:10.1007/s11095-008-9719-8

Schleef, M., Blaesen, M., Schmeer, M., Baier, R., Marie, C., Dickson, G., et al. (2010). Production of non viral DNA vectors. Curr. Gene Ther. 10, 487-507. doi:10.2174/156652310793797711

Seeliger, C., Karpinski, K., Haug, A. T., Vester, H., Schmitt, A., Bauer, J. S., et al. (2014) Five freely circulating miRNAs and bone tissue miRNAs are associated with osteoporotic fractures. J. Bone Miner. Res. 29, 1718-1728. doi:10.1002/jbmr.2175

Sen, C. K. (2011). MicroRNAs as new maestro conducting the expanding symphony orchestra of regenerative and reparative medicine. Physiol. Genomics 43, 517-520. doi:10.1152/physiolgenomics.00037.2011

Shan, Y., Luo, T., Peng, C., Sheng, R., Cao, A., Cao, X., et al. (2012). Gene delivery using dendrimer-entrapped gold nanoparticles as nonviral vectors. Biomaterials 33, 3025-3035. doi:10.1016/j.biomaterials.2011.12.045

Sheyn, D., Kimelman-Bleich, N., Pelled, G., Zilberman, Y., Gazit, D., and Gazit, Z. (2008). Ultrasound-based nonviral gene delivery induces bone formation in vivo. Gene Ther. 15, 257-266. doi:10.1038/sj.gt.3303070

Shum, K. T., Chan, C., Leung, C. M., and Tanner, J. A. (2011). Identification of a DNA aptamer that inhibits sclerostin's antagonistic effect on Wnt signalling. Biochem. J. 434, 493-501. doi:10.1042/bj20101096

Smucker, J. D., Rhee, J. M., Singh, K., Yoon, S. T., and Heller, J. G. (2006). Increased swelling complications associated with off-label usage of rhBMP-2 in the anterior cervical spine. Spine 31, 2813-2819. doi:10.1097/01.brs.0000245863.52371.c2

Sonnet, C., Simpson, C. L., Olabisi, R. M., Sullivan, K., Lazard, Z., Gugala, Z., et al. (2013). Rapid healing of femoral defects in rats with low dose sustained BMP2 expression from PEGDA hydrogel microspheres. J. Orthop. Res. 31, 1597-1604. doi:10.1002/jor.22407

Tarkka, T., Sipola, A., Jamsa, T., Soini, Y., Yla-Herttuala, S., Tuukkanen, J., et al. (2003). Adenoviral VEGF-A gene transfer induces angiogenesis and promotes bone formation in healing osseous tissues. J. Gene Med. 5, 560-566. doi:10.1002/ jgm.392

Tatum, E. L. (1966). Molecular biology, nucleic acids, and the future of medicine Perspect. Biol. Med. 10, 19-32. doi:10.1353/pbm.1966.0027

Tros de Ilarduya, C., Sun, Y., and Düzgünes, N. (2010). Gene delivery by lipoplexes and polyplexes. Eur. J. Pharm. Sci. 40, 159-170. doi:10.1016/j.ejps.2010.03.019

Tsuda, H., Wada, T., Ito, Y., Uchida, H., Dehari, H., Nakamura, K., et al. (2003). Efficient BMP2 gene transfer and bone formation of mesenchymal stem cells by a fiber-mutant adenoviral vector. Mol. Ther. 7, 354-365. doi:10.1016/S15250016(02)00062-X

van Griensven, M., Lobenhoffer, P., Barke, A., Tschernig, T., Lindenmaier, W., Krettek, C., et al. (2002). Adenoviral gene transfer in a rat fracture model. Lab. Anim. 36, 455-461. doi:10.1258/002367702320389134

van Wijnen, A. J., Van De Peppel, J., Van Leeuwen, J. P., Lian, J. B., Stein, G. S., Westendorf, J. J., et al. (2013). MicroRNA functions in osteogenesis and dysfunctions in osteoporosis. Curr. Osteoporos. Rep. 11, 72-82. doi:10.1007/s11914013-0143-6

Wegman, F., Bijenhof, A., Schuijff, L., Oner, F. C., Dhert, W. J., and Alblas, J. (2011). Osteogenic differentiation as a result of BMP-2 plasmid DNA based gene therapy in vitro and in vivo. Eur. Cell. Mater. 21, 230-242.

Wolff, J. A., and Lederberg, J. (1994). An early history of gene-transfer and therapy. Hum. Gene Ther. 5, 469-480. doi:10.1089/Hum.1994.5.4-469

Won, Y.-W., Lim, K. S., and Kim, Y.-H. (2011). Intracellular organelle-targeted nonviral gene delivery systems. J. Control. Release 152, 99-109. doi:10.1016/j.jconrel. 2011.01 .013

Woo, E. J. (2012). Recombinant human bone morphogenetic protein-2: adverse events reported to the manufacturer and user facility device experience database. Spine J. 12, 894-899. doi:10.1016/j.spinee.2012.09.052

Wu, G. P., He, X. C., Hu, C. B., Li, D. P., Yang, Z. H., and Guo, L. (2012). Effect of electroporation-mediated transfecting recombinant plasmid pIREShBMP2-hVEGF165 on mandibular distraction osteogenesis. Ann. Plast. Surg. 69, 316-325. doi:10.1097/SAP.0b013e3182119275 
Xu, X. L., Tang, T., Dai, K., Zhu, Z., Guo, X. E., Yu, C., et al. (2005). Immune response and effect of adenovirus-mediated human BMP-2 gene transfer on the repair of segmental tibial bone defects in goats. Acta Orthop. 76, 637-646. doi:10.1080/17453670510041709

Yan, J., Zhang, C., Zhao, Y., Cao, C., Wu, K., Zhao, L., et al. (2014). Non-viral oligonucleotide antimiR-138 delivery to mesenchymal stem cell sheets and the effect on osteogenesis. Biomaterials 35, 7734-7749. doi:10.1016/j.biomaterials.2014. 05.089

Yang, H. S., La, W. G., Cho, Y. M., Shin, W., Yeo, G. D., and Kim, B. S. (2012). Comparison between heparin-conjugated fibrin and collagen sponge as bone morphogenetic protein-2 carriers for bone regeneration. Exp. Mol. Med. 44, 350-355. doi:10.3858/emm.2012.44.5.039

Zhang, Y., Fan, W., Nothdurft, L., Wu, C., Zhou, Y., Crawford, R., et al. (2011). In vitro and in vivo evaluation of adenovirus combined silk fibroin scaffolds for bone morphogenetic protein-7 gene delivery. Tissue Eng. Part C Methods 17, 789-797. doi:10.1089/ten.tec. 2010.0453
Conflict of Interest Statement: The authors declare that the research was conducted in the absence of any commercial or financial relationships that could be construed as a potential conflict of interest.

Received: 02 November 2014; accepted: 14 January 2015; published online: 02 February 2015.

Citation: Balmayor ER and van Griensven M (2015) Gene therapy for bone engineering. Front. Bioeng. Biotechnol. 3:9. doi: 10.3389/fbioe.2015.00009

This article was submitted to Tissue Engineering and Regenerative Medicine, a section of the journal Frontiers in Bioengineering and Biotechnology.

Copyright (c) 2015 Balmayor and van Griensven. This is an open-access article distributed under the terms of the Creative Commons Attribution License (CC BY). The use, distribution or reproduction in other forums is permitted, provided the original author(s) or licensor are credited and that the original publication in this journal is cited, in accordance with accepted academic practice. No use, distribution or reproduction is permitted which does not comply with these terms. 